\title{
A FOLLOW-UP SERVICE-SUPPLEMENTED BY DOMICILIARY VISITS
}

\author{
By Dr. H. W. Francis Jones, M.B., M.R.C.P., D.P.M. \\ Spinal Injuries Centre, Robert Fones and Agnes Hunt \\ Orthopaedic Hospital, Ostwestry, England.
}

Social problems affecting non-disabled people can occur without materially detracting from the individual's physical health, whereas the discharged paraplegic or tetraplegic patient who runs into social or domestic difficulties is very likely to develop late complications; pressure sores in particular may occur.

At Oswestry, as in many other centres perhaps, there has been in recent years a growing strain on beds and staff, both scarce, through a continuing trickle of readmissions; many of these readmissions have been due to pressure sores and urinary infections. Relapses have occurred despite regular follow-up and these have been sufficient at times to occupy up to 20 per cent of our beds.

It has been noticed that in several instances these relapses have occurred only a few months after the patient's first discharge home. Another group has developed scores when domestic conditions have deteriorated and these relapses have often occurred several years after first discharge.

There are some patients who are particularly prone to the development of sores after discharge home and one can, at times, predict trouble of this kind. The degree of disability and the level of the lesion seem to have less to do with the liability to develop sores than the patient's personality, intelligence and adjustment. It is our common experience that the domestic and family background are of paramount importance and the ex-patient who is unfortunate in these respects is extremely vulnerable to sores.

At Oswestry I8 months ago we sought to adopt means whereby we could increase our vigilance towards patients recently discharged and at the same time give nursing advice in the patient's home.

The Robert Jones and Agnes Hunt Orthopaedic Hospital at Oswestry has a tradition of emphasis on 'after-care'; Sir Robert Jones's precepts of 50 years ago are still well remembered. Sir Robert never failed to see his patients as a whole and to consider them in their family and occupational settings. Those who work in the field of spinalinjuries are aware of the importance of the patient's domestic situation, as a study of the literature shows.

In 1957 Hardy published a report on a survey of paraplegic mineworkers; in this 59I patients were reviewed and their domestic and economic situations were fully investigated.

An interesting pilot study of home visits to paraplegic and tetraplegic expatients was published in 1967 by Thompson and Murray from Edinburgh. Here, home visits were made to IOI ex-spinal injury cases. This investigation was primarily designed to explore the possibilities and advantages of this method of follow-up, and the authors concluded that home visiting of paraplegics, some time after discharge from hospital, could be usefully undertaken in selected cases. 
Meine of Coblenz, West Germany, reported in I969 on the after-care of paralysed patients in their homes, and he commented on the particular value of home visits.

At Oswestry we have not been functioning as a spinal injuries unit long enough to have accumulated a-large population of patients in need of follow-up; we have little more than 400 on our list now. Although by the standards of this small island our clientele is scattered there are few ex-patients who live beyond a three-hour road journey from Oswestry. The Midlands spinal injuries unit at Oswestry is fortunate in having the whole-time services of an experienced medical social worker who, as in most spinal units, makes contact with welfare and housing departments as soon as the patient's prognosis is known.

\section{IMPORTANCE OF NURSING EXPERIENCE}

Even so, it was realised that nursing experience, and paraplegic nursing experience at that, was of great importance and so our senior male charge nurse was seconded to this work-domiciliary visiting. This nurse has had I3 years of experience in looking after spinal injuries and almost all the ex-patients are well known to him. Furthermore, his interest in the social and preventive aspects of paraplegic care is keen. Usually the visiting is done on one day a week; during the rest of the working week this male nurse carries out duties on the ward-largely instructional. His instructional work at the hospital takes in not only student and pupil nurses, but he also takes a hand in the instruction of rehabilitation patients and their relatives.

Domiciliary visiting to carefully selected cases began at the end of 1969 and since then 380 visits have been made to 240 different ex-patients. The total mileage covered has been about 9,000 miles and a hospital car has been made available for the purpose.

Before the visit is to be made a letter is sent to the patient and to the general practitioner concerned; when necessary a letter is also sent to the welfare or district nursing service. On several occasions the family doctor has met our follow-up nurse at the patient's home and often he has been able to meet welfare officers and district nurses.

These visits have been welcomed by the patients and they have been no less welcome to the practitioners, welfare and district nursing people. It goes without saying that much care is given to conducting these visits with great tact and professional etiquette.

We regard these home visits as having three main aims:

(a) Preventive by giving advice and instruction in the home to patients, relatives and to district nurses.

(b) Facilitating Difficult Discharges. In heavy cases, high-level tetraplegics, and in cases with social and domestic difficulties a visit may be made when the patient is still in hospital. Welfare officers are always more than willing to meet the visiting nurse at the patient's home.

(c) Finding Lost Cases. Several patients have been contacted who were becoming lost to follow-up.

How successful has this home visiting been? In work of this kind, quantification is not easy and our numbers are certainly not sufficient so far to be really 
significant. We shall have to continue this service for a further two years or more to acquire valid statistics. Even so, we are much encouraged at this stage to continue this work; the figures so far as they go at present augur well. Figures apart, there are plainly some advantages that cannot be expressed in numbers-I would mention here the eager co-operation and goodwill shown by the local authority welfare and district nursing services some of which must derive from this more personal approach; the fruit of this is a prompt and effective service to our ex-patients.

In the three years 1967,1968 and 1969 up to the start of this service the average duration of stay of readmitted pressure sore cases was over six months. During this period about 20 cases, on average, had to be readmitted annually for the treatment of sores. These sores were all too often multiple, severe and infected, sometimes with bone involvement. Thus it was that it took so long for these patients to get healed and home again.

In I970, since our home visiting began, there were 15 readmissions for sores, and the average length of stay for sore treatment was 3.5 months. This more rapid 'turn around' of cases with sores is probably due to other factors as well. We are now more quick to treat deep sores surgically-orthopaedic and plastic-and in treating multiple sores we have had heartening successes with the Keane RotorestMini Rotorest bed. Even so, we now find that only most exceptionally do we receive a readmission who is dangerously ill with deep and multiple sores.

During the past 18 months while we have been following up some of our cases in this way we have been able to be more selective in the way we readmit patients for routine reviews. In the 18 months, 22 review dates have had to be brought forward because of sores, urinary or other problems; at the same time I7 patients have seemed so well and free from trouble and some so well supervised at home by the general practitioner that in-patient review has been postponed.

Home visiting has been of great value towards the facilitating of discharge in difficult cases. In 19 cases discharge home has been assisted by one or more home visits before the patient has been discharged home. This part of the service is intended for high lesions and for patients with serious domestic difficulties; in three recent cases where both of these problems were combined all could be discharged home and have been getting on quite well since.

The need for various items of equipment has been discovered in many cases as a result of a home visit. Another feature has been the close liaison the nurse has been able to make with the welfare officers when there has been a need to make alterations to the patient's house. When confronted with the problem of a severely disabled patient both welfare officers and district nurses have been all eagerness to receive advice and help and there has never been an instance of resentment over 'sovereignty' or a 'demarcation dispute'. This has been a very pleasant aspect of this work and let us hope that it is an indication of happier times to come in this country when the partitioned and tripartite Health Services-Hospital, Local Authority and General Medical Services can come closer together as a result of the enactments now in train.

The financial cost of this service is not high, particularly as the visiting male nurse usually devotes only one day per week to this work. The cost of this home visiting service at its present level-nurse's salary and motoring costs-is approximately $£ 1000$ per annum. At Oswestry it costs, in round figures, about $£ 2000$ per annum to run each bed.

As time passes the Oswestry Spinal Injuries Unit will amass a larger population 
of ex-patients, which will bring a heavier demand on this service, and it may become embarrassingly burdened. Furthermore, the recently legislated Chronic Sick and Disabled Persons Bill may in time sufficiently strengthen all Welfare Services throughout the land so that some of this domiciliary work by a hospital nurse can be reduced.

For the present, however, it is intended to keep this part of the review service going as the results, even at this early stage, appear so promising.

\section{REFERENCES}

HARDy, A. G. (1957). Report of the Survey of Paraplegic Mineworkers. Coal Industry Social Welfare Organisation.

Thompson, M. A. \& Murray, W. A. (1967). Paraplegia at Home. Edinburgh: Livingstone. Meine, E. (1970). After-care of paralysed patient in their home. Paraplegia, 8, 3, I54. 